\title{
P53 and DNA Methylation in the Aging Process
}

\section{Yuyu Wang, Jingshan Shi*}

Department of Pharmacology and the Key Laboratory of Basic Pharmacology of Ministry of Education, Zunyi Medical University, Zunyi, China

Email: *shijs@zmu.edu.cn

How to cite this paper: Wang, Y.Y. and Shi, J.S. (2021) P53 and DNA Methylation in the Aging Process. Journal of Behavioral and Brain Science, 11, 83-95. https://doi.org/10.4236/jbbs.2021.114007

Received: Febryary 15, 2021

Accepted: April 10, 2021

Published: April 13, 2021

Copyright (C) 2021 by author(s) and Scientific Research Publishing Inc. This work is licensed under the Creative Commons Attribution International License (CC BY 4.0).

http://creativecommons.org/licenses/by/4.0/

\begin{abstract}
Healthy aging is the ultimate goal of all life science research and the most ideal state of a human being. There are many factors that affect aging, including genetic background, the environment, mental state and living habits and so on, which affect the body's internal environment and its steady state. The ultimate starting point of the body's aging all comes down to cellular aging. At the cellular level, aging is an irreversible block in the cell cycle, and the P53 gene plays a pivotal role in regulating the cell cycle. Aging is not only regulated by genes but also influenced by epigenetics affecting gene expression. DNA methylation, a novel biomarker of aging, plays a major role in epigenetics. This paper's mini-review briefly summarizes P53 and DNA methylation in aging.
\end{abstract}

\section{Keywords}

Aging, P53, DNA Methylation

\section{Introduction}

The process of human aging is complicated and individualized, taking place in the biological, psychological and social fields. Under normal conditions, aging usually refers to the progressive changes in cell metabolism and physical functions with the increase of age after adulthood. Aging results in impaired self-regulation and regeneration, and leads to structural changes. This is a natural and irreversible process [1]. Diseases or other abnormal factors can cause pathological aging, making the above phenomena appear in advance [2]. Aging is characterized by the gradual loss of some physiological functions, and it drives the development of chronic diseases, including metabolic, cardiovascular, and neoplastic diseases [3]. It is therefore a risk factor for many diseases, such as cardiovascular disease [4], cancer [5], and dementia [6]. 
One of the main signs of aging is the modification of gene expression [7], and gradually up- or down-regulated with age. Gene expression changes are mainly achieved by epigenetic modification, including several DNA modifications and histone modifications [8]. Among them, DNA methylation occupies the dominant position [9]. The correlation between the methylation level of CpG sites and the chronological age is one of the best signs of aging, and is even considered as the "apparent clock" [10]. By detecting the methylation status of CPGs in human tissue samples, the researchers found that with age, hypermethylation occurs in the promoter region, and hypomethylation occurs outside the promoter [11].

The aging of life begins with the senescence of cells. The reason for cell senescence is that the cell cycle is out of control [12]. Among the cell cycle regulation mechanism, the P53 pathway plays a crucial role [13]. The P53 is the most common mutant tumor suppressor [14]. The activation of this protein can regulate and control the aging process and senescence of cells. It has been observed that increased P53 expression in senescent cells [15].

\section{P53 Pathway and DNA Methylation}

\subsection{P53 Pathway}

The P53 signaling pathway plays an important role in many aspects, such as cell cycle regulation, development, reproduction, metabolism, senescence, tumor inhibition, etc. [16] [17]. P53 also plays a regulatory role in Alzheimer's disease, Parkinson's disease and other age-related diseases [18] [19]. As a "guardian of the genome", it is particularly important during cell growth. When cells respond to, for example, genotoxic damage, proto-oncogene activation, hypoxia, or severe stress, normal wild-type $\mathrm{P} 53$ is activated and induces a variety of biological response, such as regulating the cell cycle, participating in DNA repair, inducing apoptosis and senescence as well as regulating cell differentiation. It can even interfere with the formation and regulation of blood vessels [20] [21]. In the normal physiological systems, the expression level of the P53 is mainly controlled by the negative feedback loop of intracellular ubiquitinated with the Mouse double minute 2 (MDM2)-P53. On the one hand, the P53 can activate the MDM2 expression [22] [23] [24] [25]; on the other hand, the P53 binds to MDM2 to form an oligomer, which inhibits the transcriptional function activated by P53. The function of mouse double minute 4 (MDM4) is similar to that of MDM2 [26], which can reduce the inhibitory effect of P53 on cell proliferation and induce cell apoptosis [27].

P53 would initiate its survival mechanism under some certain conditions, for example, when the nutrition in the cell is limited, autophagy occurs to remove unnecessary or dysfunctional intracellular components, accompanied by autophagy the cell would downregulate P53 function to prevent cell damage and tissue denaturation [28]. Due to drastic changes in metabolism, the P53 maintains its survival by reshaping the metabolic pathway [28]. For example, the P53 can 
activate genes such as $\mathrm{AMPK} \beta$, TSC2, and PTEN, which suppress the mammalian target of rapamycin (mTOR, sensor of nutrient supply) signaling and the TP53-induced glycolysis and apoptotic regulator (TIGAR), regulate aerobic glycolysis and promote oxidative phosphorylation. Finally, P53 activates MDM2, indicate of its ability to destroy (called the feedback loop) the cell cycle to make it return to normal. This ability to regulate pathways can sense the availability of nutrients for cell survival and is an important P53 response to ensure homeostasis [29].

\subsection{DNA Methylation}

DNA methylation is catalyzed by DNA methyltransferases (DNMTs). The unmethylated cytosine on DNA is catalyzed by DNMT so that the fifth carbon atom is covalently linked with methyl to from 5-methylcytosine, which is provided by SAM, and SAM is converted to S-adenosine homocysteine (SAH) (Figure 1) [30]. In mammals, DNA methylation does not occur on non-CPG dinucleotide cytosine [31]. In many cases, the clusters of CpG sequence called "CpG island" are formed in the gene promoter region. Some studies have found that the overall DNA shows a low methylation status, while the DNA hypermethylation status appears locally, by copying mammalian senescent cells [32]. After the fifth carbon atom of cytosine on the CpG island of DNA is methylated, the gene expression is usually inhibited. On the contrary, demethylation can induce or reactivate gene expression. Demethylation is the conversion of methylated cytosine to unmethylated cytosine mediated by demethylase [33].

DNMTs are the managers of the conversion of unmethylated cytosines to 5-methylcytosines in mammals. They include DNMT1, DMMT3A, DNMT3b and DNMT3L, which work together to catalyze and maintain mammalian DNA methylation and methylation levels [34] [35]. In the process of aging, During DNA replication, the methylation of the hemi-methylation site is achieved by a

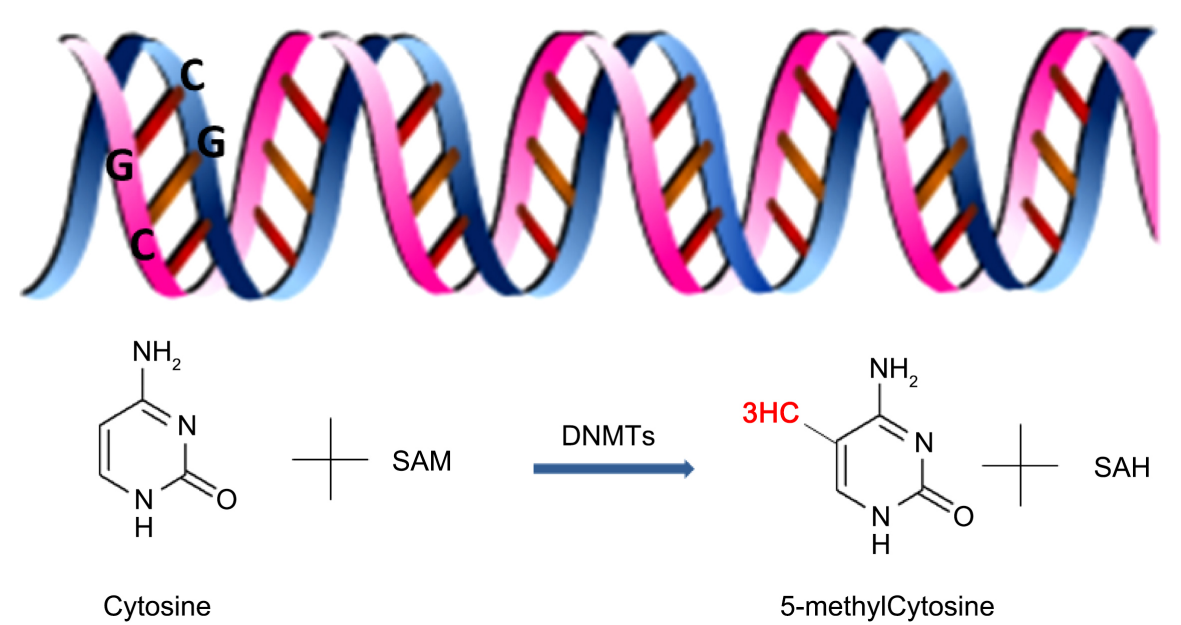

Figure 1. Under the action of methyl catalase, the methyl provided by S-adenosylmethionine (SAM) is covalently linked to the fifth carbon atom of cytosine on the double strand of DNA to form 5-methylcytosine, convert SAM into SAH. 
conservative methylation pattern by DNMT1; in this way, the production of a methylated DNA double strand using hemi-methylated DNA as a substrate is intended to stabilize the inheritance of specific DNA methylation patterns in the body [36].

There are two mechanisms to achieve DNA demethylation, including active mechanism and passive mechanism: 1) In the active mechanism, the demethylation process is mainly mediated by DNA demethyltransferase; 2) In the passive mechanism, DNA methylation cannot be completely removed because nuclear factors attach to methylated DNA in this mechanism, which can only block the effect of DNMT1. One of the demethyltransferases is the methyl-CpG binding domain 2 (Mbd2) protein, a member of the conservative methyl-CpG binding domain (MBD) family. These proteins include MBD1, MBD2, MBD3, MBD4 and Methyl-CpG binding protein 2 ( $\mathrm{MeCP} 2$ ). Methylated binding proteins specifically recognize methylated DNA and silence genes by recruiting co-repressors. MBD1 can inhibit transcription inhibition of genes, which can be partially reversed by histone acetylase inhibitors through DNA methylation, and MBD1 binds to symmetric methylated CpG sequences. It has also been found that chromatin-related factors (MCAF) containing MBD1 are considered to have a transcriptional regulatory role, through its binding to the transcriptional inhibitory domain (TRD) of MBD1 to form an inhibitory complex [37]. All MBDs may lead to silencing of regions showing DNA methylation. Therefore, there are mainly two ways to inhibit the expression of DNA methylation genes: 1) the promoter region of DNA methylation directly affects the binding of transcription activator and recognition sequence, and directly blocks the transcription of genes; 2) MBD identifies the methylated $\mathrm{CpG}$ dinucleotide sequence and recruits HDAC to the methylated site, indirectly inhibiting gene transcription under the synergistic effect of transcription factors and RNA polymerase II [38].

In addition, methylcytosine dioxygenase TET contributes to DNA demethylation. There are three members of the TET family protein, namely TET1, TET2 and TET3 [39]. The TET protein can even oxidize $5 \mathrm{~m} \mathrm{C}$ to $5 \mathrm{f} \mathrm{C}$ and $5 \mathrm{ca} \mathrm{C}$ in vitro [40]. Then thymine deoxyribonucleic acid glycosylase (TDG) converts it into unmethylated cytosine through a base excision repair mechanism [41] [42]. There is currently no consensus on how the expression of DMNTs or TETs changes with age; some studies have shown that with age, some decline, and some remain unchanged [43].

\section{P53 and DNA Methylation in Aging}

\subsection{The P53}

The most common phenotype of aging is cell senescence [44]. There are two classic pathways related to aging are P16INK4a/RB and P53/P21. P16INK4a can block the cell cycle process by inhibiting the cyclin dependent kinases4/6 (CDK4/6) complex, thereby activating $\mathrm{Rb}$ (retinoblastoma) pathway to inhibit E2F transcription [45]. 
P53 signaling pathway plays a key role in regulating cell senescence and body aging [46]. Moreover, studies have shown that an appropriate P53 expression level is very important in the process of controlling cell senescence [47]. The first identified P53 target is the cyclin dependent kinases1A (CDKN1A), commonly known as P21, which also plays an important role in cell cycle arrest and aging [48]. In normal cells, the expression of P53 is maintained at a low level through negative feedback regulation. When P53 is activated, cell proliferation is effectively inhibited by cell cycle arrest, apoptosis or senescence [49]. P53 can directly activate P21 and mediate cell cycle arrest and senescence by transcriptional induction of P21 [50] [51] [52] [53]. When P21 binds to CDK, it forms a proliferating cell nuclear complex called P21-cyclin-CDK-PCNA, which can inhibit the binding of CDK and PCNA to other molecules and thereby inactivate them [54]. The phosphorylation of $\mathrm{Rb}$ protein by $\mathrm{CDK}$ is reduced and the phosphorylation of $\mathrm{Rb}$ is blocked. $\mathrm{Rb}$ can form a complex with E2F, further hindering the transcription of E2F and negatively regulating the cell cycle, thus making the cell unable to differentiate and proliferate [55]. Increased P21Waf1/Cip1 expression and/or $\mathrm{Rb}$ activity leads to cell senescence (Figure 2) [56].

Moreover, many studies have confirmed that expression of P53 can affect aging through different pathways. For example, the pharmacological activation of P53 can promote the increase of senescence skeletal muscle stem cells in the body [57]. The activation of 53 is inhibited by fibroblast growth factor 21 (FGF21) by improving mitochondrial biogenesis and in an AMPK (AMP-activated protein kinase)-dependent manner, thereby preventing Angiotensin II (Ang II)-induced

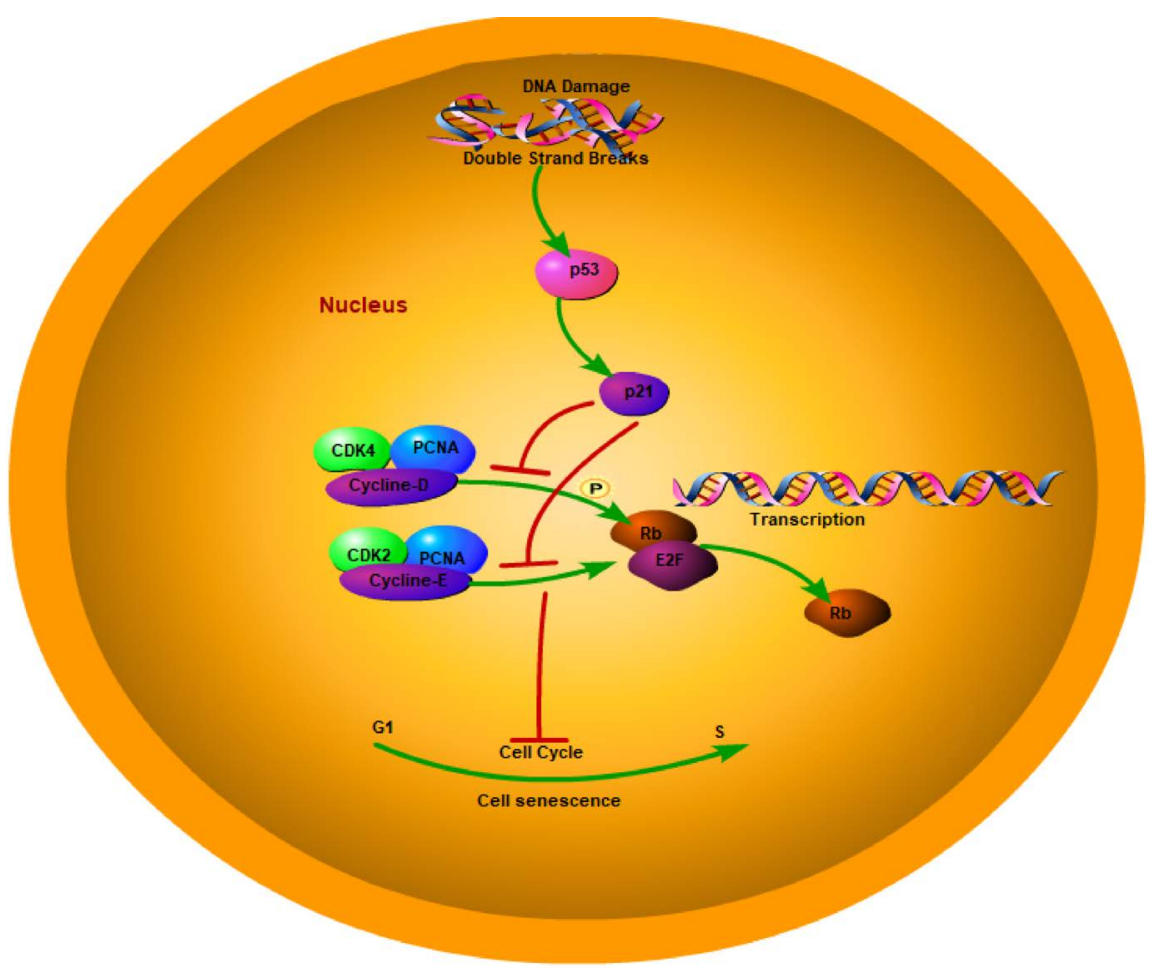

Figure 2. P53/P21 pathway in the process of aging. 
cerebrovascular aging [58]. IL-10 induces activated hematopoietic stem cell (HSC) aging by increasing P53 protein expression, thereby reducing liver fibrosis in rats [59]. With regard to the effect of P53 in human aging, there is evidence that a relatively active class of individuals carry a common P53 polypeptide variant (proline, rather than arginine), and that leads to cell cycle arrest and senescence [60]. In vivo studies on the effects and mechanisms of BZBS on age-related hypogonadism, it was found that the expression of P53 was significantly increased in the aging group, and after the administration of BZBS, it was found that the hypogonadism was alleviated pathologically, and the expression of P53 also decreased to the expression level of normal mice [61]. In the study on the anti-aging effect of mint and thyme, it was found that the activity of $\beta$-galactosidase was decreased in senile cells, but the expression of P53 protein was significantly increased [62]. P53 regulates mitochondrial dynamics through the PKA-DRP1 pathway, thereby inducing cell senescence [63].

\subsection{DNA Methylation in Aging}

Recent research suggests that epigenetics, especially DNA methylation, play a mechanistic role in aging process. The DNA methylation age, or the epigenetic clock has been shown to be highly correlated with age. Epigenetic clocks can measure changes in hundreds of specific $\mathrm{CpG}$ sites and can accurately predict the age of various species, including humans [64].

The cyclin dependent kinases1A (CDKN1A, p16 ink4a/Arf) is a cell cycle inhibitor whose expression is a mature aging marker [65], its expression is controlled by methylation and is frequently activated in various cancers [66]. Brain and muscle Arnt-like protein-1 (BMAL1) is a circadian rhythm gene associated with cell aging [67] and its expression is also regulated by epigenetic modification of DNA methylation and histone modification [68]. The study found that age-related changes in the major histocompatibility complex class 1 (MHC1) gene promoter and intra-gene methylation involved in immune function are closely related to changes in gene expression [69]. During aging, DNA methylation changes occur in tissues [70], The rDNA activity is decreased, and both its coding and promoter regions became increasingly methylated [71]. Age-related methylation was originally observed on the $\mathrm{CpG}$ island promoter of protein-coding genes [22] [72]. In mice, CpG sites with more than 20\% CpG methylation in the whole genome showed age-related variations, and methylation and hypomethylation were observed [73] [74]. In humans, the blood methylation distribution of 32 pairs of mothers and their progeny were analyzed using Illumina's human methylation 450 bead chips, and it was found that the methylation level in CpG islands at the promoters of the three genes was significantly correlated with age [75]. Another research team used a different but similar DNAm-age indicator to prove that interventions related to aging (such as calorie restriction) can reduce methylation aging in rhesus monkeys [76]. Studies have analyzed the stem cells from human exfoliated deciduous teeth (SHED) and permanent teeth of young 
(Y-DPSCs) and old (A-DPSCs) adults. In the elderly group, there is less methyl donor S-adenosylmethionine and hypomethylation of the aging marker P16 (CDNK2A) [77]. A study of 92 patients aged between 18 to 93 years old (mean age $=54.3$ years, median age $=55.5$ years $)$ of human serum DNA samples was performed with bisulphite conversion and pyrophosphoric acid sequencing, including 44 males and 48 females. Age was found to be linearly correlated with DNA methylation levels at the CpG site. Among them, 19 showed hypermethylation of ELOVL2, TRIM59, KLF14, and FHL2, while 8 showed hypomethylation of MIR29B2CHG. Nine CpG loci of ELOVL2 gene showed the strongest correlation with age, and hypermethylation showed a significant linear correlation with age $(\mathrm{R}=0.833 \sim 0.919)$. Importantly, DNA methylation levels were significantly increased at all CpG sites in the ELOVL2 gene. There were also four hypermethylated CPG loci in TRIM59 gene, which showed a significant linear relationship with age, and the methylation level increased with age [78].

\subsection{Interactions between DNA Methylation and P53}

The most important methyltransferase in DNA methylation is DNMT1, which also has the same function of regulating cell cycle as P53 [79]. P53 acts as a transcription factor in the nucleus, also mediates the regulation of DNMT1 gene expression. In the absence of genotoxic stress, P53 locates in the nucleus and binds to the common site of DNMT1 promoter, thereby blocking DNMT1 gene expression. But, when DNA damage occurs, P53 signaling pathways are activated by modification after translation or after the interaction with other transcription factors to eliminate the P53 inhibition of DNMT1, leading to a rise in DNMT1 expression [80], RB protein as downstream gene P53 pathway, not the phosphorylation of $\mathrm{RB}$ and $\mathrm{E} 2 \mathrm{~F}$ union, will raise to the $\mathrm{HDAC}$ complexes and prevent the cyclin E, PCNA and E2F-1 cell cycle protein expression level to maintain DNMT1 [81]. In addition, some researchers found the relationship between DNMT1 and P53 is not only the inhibition of the expression of DNMTA by P53, but also the interaction between DNMT1 and NEAT1, thus inhibiting the expression of P53, in the pathogenesis of lung cancer [82].

\section{Expectation and Unresolved Questions}

In the past few decades, our research on aging has never stopped; The P53-mediated effects play a vital role in the aging and the healthy aging process [83], and regulate various organs and overall aging via many ways [84] [85] [86]. Therefore, P53 may be of great value in the future research on aging and aging-related diseases. Epigenetics research has never stopped in the field of aging; there have been many studies on its relationship with aging. It has been proposed that the epigenetic changes in the aging process will lead to the decline of physical and cognitive functions; moreover, the accelerated aging of epigenetics is related to disease and all-cause mortality in old age [87]. DNA methylation is an important part of epigenetics. People are also curious about how it relates to aging. Studies 
on aging have found that the CpG of many genes has different levels of methylation associated with aging. If we can regulate the methylation of $\mathrm{CPG}$ sites, we can regulate aging. The regulation of cell cycle by P53 pathway is one of the most classical pathways in aging research. In addition, proteins related to the regulation of DNA methylation can interact with P53. However, at present, the specific genes and mechanisms of age-related DNA methylation and gene expression are not detailed and clear enough, but it is the most promising molecular marker for monitoring aging at present and warrants further investigation.

\section{Declaration of Conflicting Interests}

The authors declared no potential conflicts of interest with respect to the research, authorship, and/or publication of this article.

\section{References}

[1] Dziechciaż, M. and Filip, R. (2014) Biological Psychological and Social Determinants of Old Age: Bio-Psycho-Social Aspects of Human Aging. Annals of Agricultural and Environmental Medicine, 21, 835-838. https://doi.org/10.5604/12321966.1129943

[2] Barouki, R. (2006) Ageing Free Radicals and Cellular Stress. Medicine Sciences (Paris), 22, 266-272.

[3] Kulkarni, A., Gubbi, S. and Barzilai, N. (2020) Benefits of Metformin in Attenuating the Hallmarks of Aging. Cell Metabolism, 32, 15-30. https://doi.org/10.1016/j.cmet.2020.04.001

[4] North, B.J. and Sinclair, D.A. (2012) The Intersection between Aging and Cardiovascular Disease. Circulation Research, 110, 1097-1108. https://doi.org/10.1161/CIRCRESAHA.111.246876

[5] de Magalhães, J.P. (2013) How Ageing Processes Influence Cancer. Nature Reviews Cancer, 13, 357-365. https://doi.org/10.1038/nrc3497

[6] Querfurth, H.W. and LaFerla, F.M. (2010) Alzheimer's disease. The New England Journal of Medicine, 362, 329-344. https://doi.org/10.1056/NEJMra0909142

[7] López-Otín, C., Blasco, M.A., Partridge, L., Serrano, M. and Kroemer, G. (2013) The Hallmarks of Aging. Cell, 153, 1194-1217. https://doi.org/10.1016/j.cell.2013.05.039

[8] Handy, D.E., Castro, R. and Loscalzo, J. (2011) Epigenetic Modifications: Basic Mechanisms and Role in Cardiovascular Disease. Circulation, 123, 2145-2156. https://doi.org/10.1161/CIRCULATIONAHA.110.956839

[9] Zinovkina, L.A. and Zinovkin, R.A. (2015) DNA Methylation, Mitochondria, and Programmed Aging. Biochemistry (Moscow), 80, 1571-1577. https://doi.org/10.1134/S0006297915120044

[10] Horvath, S. and Raj, K. (2018) DNA Methylation-Based Biomarkers and the Epigenetic Clock Theory of Ageing. Nature Reviews Genetics, 19, 371-384. https://doi.org/10.1038/s41576-018-0004-3

[11] Ogrodnik, M., Salmonowicz, H., Jurk, D. and Passos, J.F. (2019) Expansion and Cell-Cycle Arrest: Common Denominators of Cellular Senescence. Trends in Biochemical Sciences, 44, 996-1008. https://doi.org/10.1016/j.tibs.2019.06.011

[12] Lazo, P.A. (2017) Reverting P53 Activation after Recovery of Cellular Stress to Resume with Cell Cycle Progression. Cellular Signalling, 33, 49-58. 
https://doi.org/10.1016/j.cellsig.2017.02.005

[13] Liu, Y., Wang, X., Wang, G., et al. (2019) The Past, Present and Future of Potential Small-Molecule Drugs Targeting P53-MDM2/MDMX for Cancer Therapy. European Journal of Medicinal Chemistry, 176, 92-104.

https://doi.org/10.1016/j.ejmech.2019.05.018

[14] Mohammadzadeh, A., Mirza-Aghazadeh-Attari, M., Hallaj, S., et al. (2019) Crosstalk between P53 and DNA Damage Response in Ageing. DNA Repair (Amst), 80, 8-15. https://doi.org/10.1016/j.dnarep.2019.05.004

[15] Tanikawa, C., Zhang, Y.Z., Yamamoto, R., et al. (2017) The Transcriptional Landscape of P53 Signalling Pathway. EBioMedicine, 20, 109-119.

https://doi.org/10.1016/j.ebiom.2017.05.017

[16] Kruiswijk, F., Labuschagne, C.F. and Vousden, K.H. (2015) P53 in Survival, Death and Metabolic Health: A Lifeguard with a Licence to Kill. Nature Reviews Molecular Cell Biology, 16, 393-405. https://doi.org/10.1038/nrm4007

[17] Riley, T., Sontag, E., Chen, P. and Levine, A. (2008) Transcriptional Control of Human P53-Regulated Genes. Nature Reviews Molecular Cell Biology, 9, 402-412. https://doi.org/10.1038/nrm2395

[18] Ashton, N.J., et al. (2020) An Update on Blood-Based Biomarkers for Non-Alzheimer Neurodegenerative Disorders. Nature Reviews Neurology, 16, 265-284. https://doi.org/10.1038/s41582-020-0348-0

[19] Talebi, M., Talebi, M., Kakouri, E., et al. (2021) Tantalizing Role of P53 Molecular Pathways and Its Coherent Medications in Neurodegenerative Diseases. International Journal of Biological Macromolecules, 172, 93-103. https://doi.org/10.1016/j.ijbiomac.2021.01.042

[20] Green, D.R. and Kroemer, G. (2009) Cytoplasmic Functions of the Tumour Suppressor P53. Nature, 458, 1127-1130. https://doi.org/10.1038/nature07986

[21] Harris, S.L. and Levine, A.J. (2005) The P53 Pathway: Positive and Negative Feedback Loops. Oncogene, 24, 2899-2908. https://doi.org/10.1038/sj.onc.1208615

[22] Ahuja, N., Li, Q., Mohan, A.L., et al. (1998) Aging and DNA Methylation in Colorectal Mucosa and Cancer. Cancer Research, 58, 5489-5494.

[23] Leng, R.P., Lin, Y., Ma, W., et al. (2003) Pirh2, a P53-Induced Ubiquitin-Protein Ligase, Promotes P53 Degradation. Cell, 112, 779-791. https://doi.org/10.1016/S0092-8674(03)00193-4

[24] Oren, M., Damalas, A., Gottlieb, T., et al. (2002) Regulation of P53: Intricate Loops and Delicate Balances. Annals of the New York Academy of Sciences, 973, 374-383. https://doi.org/10.1111/j.1749-6632.2002.tb04669.x

[25] Zhang, Y. and Lozano, G. (2017) P53: Multiple Facets of a Rubik's Cube. Annual Review of Cancer Biology, 1, 185-201. https://doi.org/10.1146/annurev-cancerbio-050216-121926

[26] Iwakuma, T. and Lozano, G. (2003) MDM2, An Introduction. Molecular Cancer Research, 1, 993.

[27] White, E. (2016) Autophagy and P53. Cold Spring Harbor Perspectives in Medicine, 6, a026120. https://doi.org/10.1101/cshperspect.a026120

[28] Berkers, C.R., Maddocks, O.D.K., Cheung, E.C., Mor, I. and Vousden, K.H. (2013) Metabolic Regulation by P53 Family Members. Cell Metabolism, 18, 617-633. https://doi.org/10.1016/j.cmet.2013.06.019

[29] Avrahami, D. and Kaestner, K.H. (2019) The Dynamic Methylome of Islets in Health and Disease. Molecular Metabolism, 27, S25-S32. 
https://doi.org/10.1016/j.molmet.2019.06.007

[30] Poon, C.H., Chan, Y.-S., Fung, M.L. and Lim, L.W. (2020) Memory and Neuromodulation: A Perspective of DNA Methylation. Neuroscience \& Biobehavioral Reviews, 111, 57-68. https://doi.org/10.1016/j.neubiorev.2019.12.022

[31] Jung, M. and Pfeifer, G.P. (2015) Aging and DNA Methylation. BMC Biology, 13, Article No. 7. https://doi.org/10.1186/s12915-015-0118-4

[32] Bhattacharya, S.K., Ramchandani, S., Cervoni, N. and Szyf, M. (1999) A Mammalian Protein with Specific Demethylase Activity for mCpG DNA. Nature, 397, 579-583. https://doi.org/10.1038/17533

[33] Bird, A. (2002) DNA Methylation Patterns and Epigenetic Memory. Genes \& Development, 16, 6-21. https://doi.org/10.1101/gad.947102

[34] Jaenisch, R. and Bird, A. (2003) Epigenetic Regulation of Gene Expression: How the Genome Integrates Intrinsic and Environmental Signals. Nature Genetics, 33, 245-254. https://doi.org/10.1038/ng1089

[35] López, V., Fernández, A.F. and Fraga, M.F. (2017) The Role of 5-Hydroxymethylcytosine in Development, Aging and Age-Related Diseases. Ageing Research Reviews, 37, 28-38. https://doi.org/10.1016/j.arr.2017.05.002

[36] Fujita, N., Watanabe, S., Ichimura, T., et al. (2003) Methyl-CpG Binding Domain 1 (MBD1) Interacts with the Suv39h1-HP1 Heterochromatic Complex for DNA Methylation-Based Transcriptional Repression. Journal of Biological Chemistry, 278, 24132-24138. https://doi.org/10.1074/jbc.M302283200

[37] Nan, X., Ng, H.-H., Johnson, C.A., et al. (1998) Transcriptional Repression by the Methyl-CpG-Binding Protein MeCP2 Involves a Histone Deacetylase Complex. Nature, 393, 386-389. https://doi.org/10.1038/30764

[38] Ito, H., Udono, T., Hirata, S. and Inoue-Murayama, M. (2018) Estimation of Chimpanzee Age Based on DNA Methylation. Scientific Reports, 8, Article No. 9998. https://doi.org/10.1038/s41598-018-28318-9

[39] Ito, S., Shen, L., Dai, Q., et al. (2011) Tet Proteins Can Convert 5-Methylcytosine to 5-Formylcytosine and 5-Carboxylcytosine. Science, 333, 1300-1303. https://doi.org/10.1126/science.1210597

[40] Wu, X. and Zhang, Y. (2017) TET-Mediated Active DNA Demethylation: Mechanism, Function and Beyond. Nature Reviews Genetics, 18, 517-534. https://doi.org/10.1038/nrg.2017.33

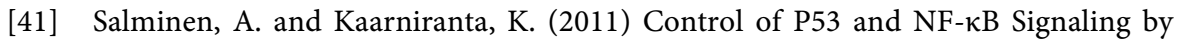
WIP1 and MIF: Role in Cellular Senescence and Organismal Aging. Cellular Signalling, 23, 747-752. https://doi.org/10.1016/j.cellsig.2010.10.012

[42] Schübeler, D. (2015) Function and Information Content of DNA Methylation. Nature, 517, 321-326. https://doi.org/10.1038/nature14192

[43] Unnikrishnan, A., Hadad, N., Masser, D.R., Jackson, J., Freeman, W.M. and Richardson, A. (2018) Revisiting the Genomic Hypomethylation Hypothesis of Aging. Annals of the New York Academy of Sciences, 1418, 69-79. https://doi.org/10.1111/nyas.13533

[44] Rufini, A., Tucci, P., Celardo, I. and Melino, G. (2013) Senescence and Aging: The Critical Roles of P53. Oncogene, 32, 5129-5143. https://doi.org/10.1038/onc.2012.640

[45] Sherr, C.J. and McCormick, F. (2002) The RB and P53 Pathways in Cancer. Cancer Cell, 2, 103-112. https://doi.org/10.1016/S1535-6108(02)00102-2

[46] Safdar, A., Annis, S., Kraytsberg, Y., et al. (2016) Amelioration of Premature Aging 
in mtDNA Mutator Mouse by Exercise: The Interplay of Oxidative Stress, PGC-1 $\alpha$, P53, and DNA Damage. A Hypothesis. Current Opinion in Genetics \& Development, 38, 127-132. https://doi.org/10.1016/j.gde.2016.06.011

[47] Maitra, S., Sornjai, W., Smith, D.R. and Vincent, B. (2021) Phenanthroline Impairs $\beta$ APP Processing and Expression, Increases P53 Protein Levels and Induces Cell Cycle Arrest in Human Neuroblastoma Cells. Brain Research Bulletin, 170, 29-38. https://doi.org/10.1016/j.brainresbull.2021.02.001

[48] Brown, J.P., Wei, W. and Sedivy, J.M. (1997) Bypass of Senescence after Disruption of P2 $1^{\mathrm{CIP} 1 / \mathrm{WAF} 1}$ Gene in Normal Diploid Human Fibroblasts. Science, 277, 831-834. https://doi.org/10.1126/science.277.5327.831

[49] Choi, O.R., Ryu, M.S. and Lim, I.K. (2016) Shifting P53-Induced Senescence to Cell Death by TIS21 ${ }^{/ \mathrm{BTG} 2 / \mathrm{Pc} 3}$ Gene through Posttranslational Modification of P53 Protein. Cellular Signalling, 28, 1172-1185. https://doi.org/10.1016/j.cellsig.2016.05.014

[50] Di Leonardo, A., Linke, S.P., Clarkin, K. and Wahl, G.M. (1994) DNA Damage Triggers a Prolonged P53-Dependent G1 Arrest and Long-Term Induction of Cip1 in Normal Human Fibroblasts. Genes \& Development, 8, 2540-2551. https://doi.org/10.1101/gad.8.21.2540

[51] Dulić, V., Kaufmann, W.K., Wilson, S.J., et al. (1994) P53-Dependent Inhibition of Cyclin-Dependent Kinase Activities in Human Fibroblasts during Radiation-Induced G1 Arrest. Cell, 76, 1013-1023. https://doi.org/10.1016/0092-8674(94)90379-4

[52] Kortlever, R.M., Higgins, P.J. and Bernards, R. (2006) Plasminogen Activator Inhibitor-1 Is a Critical Downstream Target of P53 in the Induction of Replicative Senescence. Nature Cell Biology, 8, 877-884. https://doi.org/10.1038/ncb1448

[53] El-Deiry, W.S., Tokino, T., Velculescu, V.E., et al. (1993) WAF1, a Potential Mediator of P53 Tumor Suppression. Cell, 75, 817-825.

https://doi.org/10.1016/0092-8674(93)90500-P

[54] Cmielová, J. and Rezáčová, M. (2011) P21Cip1/Waf1 Protein and Its Function Based on a Subcellular Localization [Corrected]. Journal of Cellular Biochemistry, 112, 3502-3506. https://doi.org/10.1002/jcb.23296

[55] Fernandez, S., Risolino, M., Mandia, N., et al. (2015) miR-340 Inhibits Tumor Cell Proliferation and Induces Apoptosis by Targeting Multiple Negative Regulators of P27 in Non-Small Cell Lung Cancer. Oncogene, 34, 3240-3250. https://doi.org/10.1038/onc.2014.267

[56] Liu, L., Charville, G.W., Cheung, T.H., et al. (2018) Impaired Notch Signaling Leads to a Decrease in P53 Activity and Mitotic Catastrophe in Aged Muscle Stem Cells. Cell Stem Cell, 23, 544-556.e4. https://doi.org/10.1016/j.stem.2018.08.019

[57] Fujita, K. (2019) P53 Isoforms in Cellular Senescence- and Ageing-Associated Biological and Physiological Functions. International Journal of Molecular Sciences, 20, 6023. https://doi.org/10.3390/ijms20236023

[58] Wang, X.M., Xiao, H., Liu, L.L., et al. (2016) FGF21 Represses Cerebrovascular Aging via Improving Mitochondrial Biogenesis and Inhibiting P53 Signaling Pathway in an AMPK-Dependent Manner. Experimental Cell Research, 346, 147-156. https://doi.org/10.1016/j.yexcr.2016.06.020

[59] Huang, Y.-H., Chen, M.-H., Guo, Q.-L., et al. (2020) Interleukin-10 Induces Senescence of Activated Hepatic Stellate Cells via STAT3-P53 Pathway to Attenuate Liver Fibrosis. Cellular Signalling, 66, 109445.

https://doi.org/10.1016/j.cellsig.2019.109445

[60] Carrasco-Garcia, E., Moreno, M., Moreno-Cugnon, L. and Matheu, A. (2017) In- 
creased Arf/P53 Activity in Stem Cells, Aging and Cancer. Aging Cell, 16, 219-225. https://doi.org/10.1111/acel.12574

[61] Li, L., Chen, B., An, T., et al. (2021) BaZiBuShen Alleviates Altered Testicular Mor-

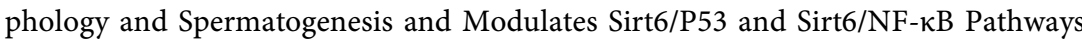
in Aging Mice Induced by D-Galactose and $\mathrm{NaNO}_{2}$. Journal of Ethnopharmacology, 271, 113810. https://doi.org/10.1016/j.jep.2021.113810

[62] Sarikhani, M., Deylam, M., Alizadeh, E., et al. (2021) Anti-Aging Effects of Peppermint (Mentha piperita L.) and Shirazi Thyme (Zataria multiflora Boiss.) Plant Extracts. Food Bioscience, 41, 100930. https://doi.org/10.1016/j.fbio.2021.100930

[63] Kim, Y.Y., Um, J.-H., Shin, D.J., Jeong, D.J., Hong, Y.B. and Yun, J. (2021) P53-Mediated Regulation of Mitochondrial Dynamics Plays a Pivotal Role in the Senescence of Various Normal Cells as Well as Cancer Cells. The FASEB Journal, 35, e21319. https://doi.org/10.1096/fj.202002007R

[64] Unnikrishnan, A., Freeman, W.M., Jackson, J., et al. (2019) The Role of DNA Methylation in Epigenetics of Aging. Pharmacology \& Therapeutics, 195, 172-185. https://doi.org/10.1016/j.pharmthera.2018.11.001

[65] Krishnamurthy, J., Torrice, C., Ramsey, M.R., et al. (2004) Ink4a/Arf Expression Is a Biomarker of Aging. Journal of Clinical Investigation, 114, 1299-1307. https://doi.org/10.1172/JCI22475

[66] Matsuda, Y., Ichida, T., Matsuzawa, J., Sugimura, K. and Asakura, H. (1999) pl6INK4 Is Inactivated by Extensive CpG Methylation in Human Hepatocellular Carcinoma. Gastroenterology, 116, 394-400. https://doi.org/10.1016/S0016-5085(99)70137-X

[67] Khapre, R.V., Kondratova, A.A., Susova, O. and Kondratov, R.V. (2011) Circadian Clock Protein BMAL1 Regulates Cellular Senescence in Vivo. Cell Cycle, 10, 4162-4169. https://doi.org/10.4161/cc.10.23.18381

[68] Sahar, S. and Sassone-Corsi, P. (2013) The Epigenetic Language of Circadian Clocks. In: Kramer, A. and Merrow, M., Eds., Circadian Clocks. Handbook of Experimental Pharmacology, Springer, Berlin, Heidelberg, 29-44.

https://doi.org/10.1007/978-3-642-25950-0_2

[69] Mangold, C.A., Wronowski, B., Du, M., et al. (2017) Sexually Divergent Induction of Microglial-Associated Neuroinflammation with Hippocampal Aging. Journal of Neuroinflammation, 14, Article No. 141. https://doi.org/10.1186/s12974-017-0920-8

[70] Cardelli, M. (2018) The Epigenetic Alterations of Endogenous Retroelements in Aging. Mechanisms of Ageing and Development, 174, 30-46. https://doi.org/10.1016/j.mad.2018.02.002

[71] Shao, F., Liu, X., Zhang, X., et al. (2021) Methylation of 45S Ribosomal DNA (rDNA) Is Associated with Cancer and Aging in Humans. International Journal of Genomics, 2021, Article ID: 8818007. https://doi.org/10.1155/2021/8818007

[72] Issa, J.P., Ottaviano, Y.L., Celano, P., et al. (1994) Methylation of the Oestrogen Receptor CpG Island Links Ageing and Neoplasia in Human Colon. Nature Genetics, 7, 536-540. https://doi.org/10.1038/ng0894-536

[73] Issa, J.-P. (2014) Aging and Epigenetic Drift: A Vicious Cycle. Journal of Clinical Investigation, 124, 24-29. https://doi.org/10.1172/JCI69735

[74] Maegawa, S., Hinkal, G., Kim, H.S., et al. (2010) Widespread and Tissue Specific Age-Related DNA Methylation Changes in Mice. Genome Research, 20, 332-340. https://doi.org/10.1101/gr.096826.109

[75] Garagnani, P., Bacalini, M.G., Pirazzini, C., et al. (2012) Methylation of ELOVL2 Gene as a New Epigenetic Marker of Age. Aging Cell, 11, 1132-1134. 
https://doi.org/10.1111/acel.12005

[76] Maegawa, S., Lu, Y., Tahara, T., et al. (2017) Caloric Restriction Delays Age-Related Methylation Drift. Nature Communications, 8, Article No. 539.

https://doi.org/10.1038/s41467-017-00607-3

[77] Yang, R.L., Huang, H.M., Han, C.S., et al. (2020) Serine Metabolism Controls Dental Pulp Stem Cell Aging by Regulating the DNA Methylation of P16. Journal of Dental Research, 100, 90-97. https://doi.org/10.1177/0022034520958374

[78] Al-Ghanmy, H.S.G., Al-Rashedi, N.A.M. and Ayied, A.Y. (2021) Age Estimation by DNA Methylation Levels in Iraqi Subjects. Gene Reports, 23, Article ID: 101022.

[79] Schoofs, T., Berdel, W.E. and Müller-Tidow, C.J.L. (2014) Origins of Aberrant DNA Methylation in Acute Myeloid Leukemia. Leukemia, 28, 1-14. https://doi.org/10.1038/leu.2013.242

[80] Enane, F.O., Saunthararajah, Y. and Korc, M. (2018) Differentiation Therapy and the Mechanisms That Terminate Cancer Cell Proliferation without Harming Normal Cells. Cell Death \& Disease, 9, 912.

[81] Kinney, S.R. and Pradhan, S. (2011) Chapter 9. Regulation of Expression and Activity of DNA (Cytosine-5) Methyltransferases in Mammalian Cells. Progress in Molecular Biology and Translational Science, 101, 311-333. https://doi.org/10.1016/B978-0-12-387685-0.00009-3

[82] Ma, F., Lei, Y.Y., Ding, M.G., et al. (2020) LncRNA NEAT1 Interacted with DNMT1 to Regulate Malignant Phenotype of Cancer Cell and Cytotoxic T Cell Infiltration via Epigenetic Inhibition of P53, cGAS, and STING in Lung Cancer. Frontiers in Genetics, 11. https://doi.org/10.3389/fgene.2020.00250

[83] Ou, H.L. and Schumacher, B. (2018) DNA Damage Responses and P53 in the Aging Process. Blood, 131, 488-495. https://doi.org/10.1182/blood-2017-07-746396

[84] Yamaguchi, Y., Kaida, K., Suenaga, Y., et al. (2020) Age-Related Dysfunction of P53-Regulated Phagocytic Activity in Macrophages. Biochemical and Biophysical Research Communications, 529, 462-466. https://doi.org/10.1016/j.bbrc.2020.05.121

[85] Wu, L., Liu, D., Wu, Y., et al. (2019) P53 Mediated Transcription of Omi/HtrA2 in Aging Myocardium. Biochemical and Biophysical Research Communications, 519, 734-739. https://doi.org/10.1016/j.bbrc.2019.09.062

[86] Wang, L., Chen, M., Fu, H., Ni, T. and Wei, G. (2020) Tempo-Spatial Alternative Polyadenylation Analysis Reveals That 3' UTR Lengthening of Mdm2 Regulates P53 Expression and Cellular Senescence in Aged Rat Testis. Biochemical and Biophysical Research Communications, 523, 1046-1052. https://doi.org/10.1016/j.bbrc.2020.01.061

[87] Degerman, S., Josefsson, M., Adolfsson, A.N., et al. (2017) Maintained Memory in Aging Is Associated with Young Epigenetic Age. Neurobiology of Aging, 55, 167-171. https://doi.org/10.1016/j.neurobiolaging.2017.02.009 